\title{
Ultrasonic testing of laboratory samples representing monopile wind turbine foundations
}

\author{
${ }^{1 *}$ Gunn, D.A., ${ }^{1}$ Holyoake, S., ${ }^{1}$ Dashwood, B., ${ }^{1}$ Wilkinson, P.B., ${ }^{2}$ Brett, C.R., ${ }^{1}$ Wallis, H.C., ${ }^{1}$ Leman, W. \\ \& ${ }^{1}$ Rees, $\mathbf{J}$. \\ 1 - British Geological Survey, Environmental Science Centre, Keyworth, Nottingham, NG12 5GG \\ 2 - Uniper Technologies Ltd, Ratcliffe-on-Soar, Nottingham, NG11 0EE \\ * Corresponding author: $\underline{\text { dgu@ @gs.ac.uk }}$
}

\begin{abstract}
Wind energy turbines and offshore hydrocarbons platforms rely on injected concrete grout to support and transfer loads between steel substructures. Deterioration of this grout under large operational stresses can lead to the loss of bonding, formation of gaps, crushing and the loss of grout from the annulus between the steel substructures. In this paper, the integrity of the grout between two steel panels is experimentally tested using a low-frequency ultrasound backscatter method [1]. The experimental results and modelled outcomes [1] are compared for grout condition classes including: good condition, gaps between the grout and either steel panel and the complete absence of grout. Pearson's correlation coefficients of over $83 \%$ were observed when comparing the notch magnitudes and frequencies and on the modelled and experimental reflectance spectra from front and rear gap, and missing grout conditions. Kolmogorov-Smirnov similarity tests on the modelled and experimental notch magnitudes indicate a $20 \%$ significance on the rear gap and front gap spectra and a $10 \%$ significance on the missing grout spectra. The significances of these tests support the potential application of backscattered low-frequency ultrasound for grout condition inspection. However, development of automated condition recognition algorithms based either on spectral characteristics or on time-localised spectral features of the backscatter, is required to make routine inspection commercially viable.
\end{abstract}

Keywords: Wave propagation testing; reflection spectrum; low-frequency ultrasound; concrete grout

\section{Introduction}

\subsection{Wind Turbine Foundations}

Both the hydrocarbon extraction and renewable energy industries are heavily reliant upon offshore platforms and infrastructure constructed on the seabed of the shallow seas about the UK. While the platform designs vary to suit water depth, injected concrete grout is commonly used to transfer the loads between steel sub-structures within their foundations. For example, wind turbines utilise a range of foundation designs including the gravity or monopile foundation for shallow water $(<30 \mathrm{~m})$ or the tripod foundation for deeper water (to $60 \mathrm{~m}$ ). The foundations in all cases incorporate load transfer through steel-concretesteel substructures such as the monopile concept shown in Fig. 1a.

The preferred approach for many wind turbines in the UK Licence Round 1 was for a driven monopile (MP) with a Transition Piece (TP) grouted onto it as a spigot joint (Fig. 1a). The concrete is subjected to large, complex stresses [2], leading to progressive deterioration in the foundation condition manifest in a range of defects such as debonding and the growth of gaps at its interfaces with the steel sub-structures, or even a complete loss of concrete in parts of the annulus [3]. The Carbon Trust (2017) [4] suggest that up to $40 \%$ of the early (UK and European) monopile fleet are affected by problems with bond-cracking, grout crushing and tower slippage along grouted joints. Inspection of the grout condition in these joints is therefore a key priority for the industry.

Fig. 1. Principal foundation for offshore infrastructure constructed on the seabed.

a. Schematic section through a wind turbine monopile foundation structure.

b. Concept of reverberating ultrasound within each layer of the foundation structure.

\subsection{Inspection Challenge}

The capabilities of several NDT techniques to determine the foundation structure and condition have been evaluated by the wind energy community, including gamma radiography, impulse-response testing, guided 
waves, pulse-echo and array ultrasonic testing [3]. Methods requiring two-sided access across the structure were considered impractical due to uncertainties in coupled sensor positioning and alignment. Using ultrasound at $\mathrm{MHz}$ frequencies, insufficient echo amplitudes could be gathered to indicate the condition of even the nearest steel-grout interface, and this method could not satisfactorily differentiate water-filled gaps from fully bonded grout [3]. Excessive attenuation at high frequencies inhibited penetration into the target, making standard ultrasound sonography unsuitable in these cases, due to poor sensitivity. However, Wilkinson et al. (2018) [1] demonstrated theoretically and experimentally that use of low-frequency sound could overcome the problem of penetration but required analysis in the spectral domain in order to understand the structure of layered media.

The foundation substructure can be represented by a 3-layer system bound by water inside the cylindrical pile and the open sea surrounding the transition piece, shown by the inset in Fig. 1a. Even a single, finite thickness layer immersed in water has two interfaces across which incident sound is partially transmitted and reflected, e.g. at $\mathrm{x}=0$ and $\mathrm{L}$ in Fig. 1b. At a frequency where the layer thickness is approximately equivalent to half the wavelength of the sound wave propagating in each layer, the reflectance of the plate reduces to a minimum (controlled by the losses in the materials - Fig. 1b). This first minimum is equivalent to the fundamental half-wavelength resonance though the layer $[5,6,7,1]$. Further notches appear where the reflectance diminishes to local minima at frequencies where the thickness is equivalent to multiples of the fundamental half-wavelength resonance (Fig. 1b).

The nominal 'as designed' dimension for many wind turbines incorporates a $70 \mathrm{~mm}$ thick concrete grout between mild steel monopile and transition pieces, each $50 \mathrm{~mm}$ thick. However, in situ, the thickness of the steel plates may deviate from $50 \mathrm{~mm}$ and the thickness of the grout may not be uniform throughout the annulus due to deviation of the transition piece away from the central position. The inset in Fig. 1b shows how a normally incident sound wave is partially transmitted and reflected at both the external boundaries between the foundation and the surrounding water and at internal boundaries between the grout annulus and steel structures. 1D wave propagation modelling by Wilkinson et al. (2018) [1] indicated the equivalent single layer, half-wavelength resonances for these materials (with the above dimensions) occurred at approximately $59 \mathrm{kHz}$ in the steel and $33.5 \mathrm{kHz}$ in the grout. Local minima occur at these resonance frequencies forming 'notch' features on the reflectance spectrum. Similar resonance phenomena occur within these same layers when they are within a layered medium. Hence the spectral characteristics of a reflected echo from a composite of these material layers exhibit missing energy or notches that occur about frequencies associated resonances within the composite layers comprising a layered system. In the case of the wind turbine section in Fig. 1b, notches will occur around 33.5 and $59 \mathrm{kHz}$ in relation to the grout and steel components respectively.

Wilkinson et al. (2018) [1] also showed that introduction of small water-filled gaps between the steel and concrete layers further modified the reflectance spectra. Building on the work by Wilkinson et al. (2018) [1], this paper compares the spectral characteristics of both modelled and experimental echoes resulting from the reflection of a frequency-modulated chirp from a range of 3-layered systems representing a wind turbine foundation in varying condition states. Ultimately, this paper aims to verify the modelled outcomes presented by Wilkinson et al. (2018) [1] by demonstrating compatible experimental reflections from full thickness scale physical models of the wind turbine foundation, and by so doing, underline the viability of a low-frequency ultrasound method for inspecting the condition of the concrete grout.

\section{Test Programme}

This research involved a matrix of tests to compare numerical and experimental echo spectra from a 3-layer foundation model in different condition states. The matrix tested four key states (Fig. 2a), including:

i. Good condition: concrete grout in contact with both steel plates;

ii. Front gap: gaps of varying apertures at the interface between the concrete and the front steel plate;

iii. Rear gap; gaps of varying apertures at the interface between the concrete and the rear steel plate;

iv. Missing grout; water in gaps of variable widths between the steel plates.

The experimental method and results are described in this paper and compared to equivalent outcomes from a 1D wave propagation transfer matrix model that is explained in Wilkinson et al. (2018). The experimental 
study also included tests on single $50 \mathrm{~mm}$ thick mild steel and $70 \mathrm{~mm}$ thick moulded grout layers to establish the material property parameters, e.g. ultrasound velocity and attenuation for input into the numerical models.

Fig. 2. Experimental echo reflection tests from the physical foundation condition models.

a. Incident ultrasound relative to the four key foundation model condition states.

b. Steel-Grout bond: steel cleaned and araldite applied over mould surface.

c. Steel-Grout bond: $70 \mathrm{~mm}$ grout block clamped to underlying steel while araldite cures.

\subsection{Test Targets}

Two mild steel plates, each of nominal dimensions $300 \mathrm{~mm}$ by $300 \mathrm{~mm}$ by $50 \mathrm{~mm}$ thick, were used in the single layer tests, and also combined with a central concrete grout in the 3-layer target tests. Both steel plates were flat/parallel to within $0.5 \mathrm{~mm}$. Grout supplied as dry Ducorit Densit S5 [8] concrete (including aggregate) was mixed with water and moulded to one of the steel plates. Loose films of rust were removed from the steel face using a wire brush, after which the face was wiped clean with a cloth soaked in water and mild detergent. Wooden shuttering was built up from the face of one of the steel samples that was horizontally levelled and onto which the grout was set to provide an initial mould nominally of $300 \mathrm{~mm} \mathrm{x}$ $300 \mathrm{~mm}$ by $80 \mathrm{~mm}$ thick. The moulded sample was covered with a damp cloth and allowed to cure for several weeks before being removed from the steel and taken for cutting and surface grinding to a nominal thickness of $70 \mathrm{~mm}$ (where the parallelism was measured to within $0.5 \mathrm{~mm}$ ) for use in the single and multiple layer experiments. The experimental programme proceeded firstly with the single layer tests, followed by the missing grout (water gap) test and finally the good condition, rear and front gap tests.

Testing on layered samples representing good condition and also with gaps introduced at the front and rear interfaces was undertaken on steel-grout-steel systems in which the grout and the first steel plate were bonded on the original mould face. The bonding agent was slow-curing, high-strength araldite and various steps were undertaken to ensure a close fit between the steel and the grout. The mould face of the steel was rubbed down with wire wool to remove any loose film or material. Residual dust was wiped away from both the mould faces using a cloth dampened with mild soapy water. The araldite was mixed and applied to the dry steel face, Fig. 2b. The grout was repositioned over the steel face and a clamping force around the edges was applied to encourage an even and close fit across the interface while the epoxy cured, Fig. 2c. The second steel plate was positioned over the surface-ground face of the grout and the complete 3-layer target was tightly clamped using C-clamps at each of the four corners.

\subsection{Experimental Test Set-up}

The fundamental set-up simply required positioning of the ultrasonic transducer, which acted as a transceiver to transmit pulses towards and receive normally incident echoes reflected from the target under test, Fig. 3. Fig. 3 also shows how the echo reflected from the test target differed from the original transmitted pulse, in that it was modulated by the complex partial transmission and reflection processes presented by the target structural interfaces. Digital electrical test signals sent from a PC computer were generated by a PC-based Arbitrary Waveform Generator (AWG), which was connected to the ultrasonic transducer. The transducer converted the electrical signal into an equivalent ultrasound pressure wave, which propagated through the water and reflected from the external and internal interfaces of the test targets. The transducer converted the reflected ultrasound pressure wave back to an electrical signal, which was digitised by the Digital Storage Oscilloscope (DSO) and stored in a file on the computer hard disk. The file provided the input time series for spectral analysis using Fourier Transform methods.

\section{Fig. 3. Experimental set-up and instrumentation used to record reflected and transmitted signals.}

\subsection{Test Procedures}

The echo-reflection tests utilised an ultrasound sensor with a peak sensitivity at $63.5 \mathrm{kHz}$ to generate a sequence of frequency-modulated chirps covering $10 \mathrm{kHz}$ to $120 \mathrm{kHz}$. The active piezo-electric element in the transducer had a face size of $155 \mathrm{~mm} \times 155 \mathrm{~mm}$ square (approximately $45 \mathrm{~mm}$ thick). This transducer produced a central lobe that spread at between $+/-28^{\circ}(15 \mathrm{kHz})$ and $+/-7^{\circ}(80 \mathrm{kHz})$. A beam angle of $+/-$ 
$10^{\circ}$ produces an equivalent central lobe spot dimension of $296 \mathrm{~mm}$ at $0.4 \mathrm{~m}$, which was considered a suitable transducer-target offset. However, to avoid overlapping transmitted and received signals, a pulse width of $400 \mu$ s was used and the complete frequency range from $10 \mathrm{kHz}$ to $120 \mathrm{kHz}$ was delivered using four successive cosine frequency-modulated (CFM) chirps, including: 1. 10-60 kHz; $2.30-80 \mathrm{kHz} ; 3.50-$ $100 \mathrm{kHz}$; and 4. 70-120 kHz. Cosine modulation results in the most gradual frequency change at the start and end of the signal, which was combined with a $5 \mathrm{kHz}$ amplitude-taper to inhibit the impulse response and reduce beating of the transducer, Fig 4 . The transducer sensitivity function was determined via recording echo reflections of this signal series from the air-water interface set $0.4 \mathrm{~m}$ away from the transducer, Fig. 4. This sensitivity function will be superimposed onto the reflectance characteristics of the targets, and so it was convolved with the numerically-modelled reflection spectra to enable a like-for-like comparison with the experimental data.

Fig. 4. Measuring the transducer sensitivity function using echo from the air-water interface.

a. Transducer in tank directed at the water surface for air-water reflection test.

b. Series of received signals for the successive CFM chirps (each with a $50 \mathrm{kHz}$ frequency range).

c. Transducer sensitivity function constructed from the envelope of the spectral response to each of the CFM signals.

\section{Test Results}

\subsection{Single Layer Targets}

\subsubsection{Steel}

Table 1 shows the measured physical properties (dimensions and density) of the steel and grout samples used to construct the composite 'foundation' targets, and also provides the ultrasound velocity and attenuation properties used in the numerical models. Notches on the experimental spectra of echoes from both single steel plates at $56.5 \mathrm{kHz}$ are associated with the fundamental half-wavelength resonance through the steel. Application of the approximate half-wavelength resonance provided by Wilkinson et al. (2018) [1] indicates a velocity of $5707 \mathrm{~m} . \mathrm{s}^{-1}$, equal to twice the product of the steel thickness and notch frequency, Fig. 5a. This approximation only holds for a lossless medium, whereas an attenuation of $1 \mathrm{~Np} . \mathrm{m}^{-1}$ was used to fit the experimental data. Note that the samples were supplied by an industry partner as representative of the steel used in wind turbine foundations, and have velocities that are towards the low end of the range expected for mild steel, which may have been caused by additives or work softening, e.g. during the rolling process. Fig. 5a also shows a spectrum modelled using the ultrasound propagation properties in Table 1, which exhibits a resonance notch at $59.2 \mathrm{kHz}$, where the modelled velocity is $5889 \mathrm{~m} . \mathrm{s}^{-1}$ at this frequency (and not the $5977 \mathrm{~m} . \mathrm{s}^{-1}$ predicted using the simple formula that assumes a lossless medium). The numerical models used a linear function to accommodate the velocity dispersion (shown in Fig. 5b), which overestimates the fundamental resonance frequency but provides a good fit to the second harmonic of resonance through the steel at $118.4 \mathrm{kHz}$, (although note that the transducer exhibits relatively low sensitivity $(<-20 \mathrm{~dB})$ at these frequencies $)$.

Fig. 5. Reflection spectra of single steel layers used to construct composite targets.

a. $\quad$ Echo spectra: Solid plots = Experimental; Red dashed plot = Model using properties in Table 1 convolved with transducer sensitivity function.

Y-axis: Spectral amplitude (Volts); X-axis: kHz;

b. $\quad$ Equivalent experimental reflectance spectra: Solid plots = Experimental; Red dashed plot = Modelled using properties in Table 1. Y-axis: Relative spectral amplitude normalised by transducer sensitivity function; X-axis: kHz; 


\begin{tabular}{|c|c|c|c|c|c|c|c|c|c|}
\hline \multicolumn{10}{|c|}{ Grout Properties } \\
\hline Thickness & 1 & 2 & 3 & 4 & 5 & 6 & 7 & 8 & Mean \\
\hline $\mathrm{mm}$ & 69.79 & 69.81 & 69.89 & 70.07 & 70.08 & 70.22 & 70.02 & 70.03 & 69.99 \\
\hline Length & 1 & 2 & 3 & Mean & & & & & \\
\hline $\mathrm{mm}$ & 299.45 & 300.25 & 299.73 & 299.81 & & & & & \\
\hline Width & 1 & 2 & 3 & Mean & & & & & \\
\hline $\mathrm{mm}$ & 299.9 & 299.7 & 298.35 & 299.32 & & & & & \\
\hline Density & 2.468 & Mg. $\mathrm{m}^{-3}$ & & Velocity & \multicolumn{4}{|c|}{$V(f)=4494.8+4.8087 . f-0.0133 . f^{2}$} & $\mathrm{~m} \cdot \mathrm{s}^{-1}$ \\
\hline Attenuatic & & \multicolumn{3}{|c|}{$\alpha(f)=0.277+0.0162 . f$} & Np.m ${ }^{-1}$ & \multicolumn{4}{|c|}{ where $f=$ frequency in $\mathrm{kHz}$} \\
\hline \multicolumn{10}{|c|}{ Steel Properties [Two samples: S1 upper rows; S2 lower rows] } \\
\hline Thickness & 1 & 2 & 3 & 4 & 5 & 6 & 7 & 8 & Mean \\
\hline mm S1-> & 50.45 & 50.50 & 50.49 & 50.49 & 50.44 & 50.51 & 50.47 & 50.48 & 50.48 \\
\hline S2-> & 50.59 & 50.91 & 50.57 & 50.59 & 50.56 & 50.50 & 50.65 & 50.73 & 50.64 \\
\hline Length & 1 & 2 & 3 & Mean & & & & & \\
\hline \multirow[t]{2}{*}{$\mathrm{mm}$} & 299.29 & 299.18 & 299.05 & 299.17 & $<-S 1$ & & & & \\
\hline & 299.23 & 299.86 & 299.41 & 299.50 & $<-S 2$ & & & & \\
\hline Width & 1 & 2 & 3 & Mean & & & & & \\
\hline \multirow[t]{2}{*}{$\mathrm{mm}$} & 299.17 & 299.33 & 298.91 & 299.14 & $<-\mathrm{S1}$ & & & & \\
\hline & 299.67 & 299.65 & 299.6 & 299.64 & $<-S 2$ & & & & \\
\hline Density & 7.846 & Mg. $\mathrm{m}^{-3}$ & & Velocity & \multicolumn{4}{|c|}{$V(f)=5849.4+0.6748 . f$} & $\mathrm{~m} \cdot \mathrm{s}^{-1}$ \\
\hline \multicolumn{2}{|c|}{ Attenuation } & \multicolumn{3}{|l|}{$\alpha(f)=1$} & Np. $\mathrm{m}^{-1}$ & \multicolumn{4}{|c|}{ where $f=$ frequency in $\mathrm{kHz}$} \\
\hline
\end{tabular}

Table 1: Measured grout and steel layer properties used to model the reflectance spectra.

\subsubsection{Grout}

Notches on the experimental echo spectrum from the grout occurred at 35.0 (fundamental half-wavelength resonance), 72.5 ( $2^{\text {nd }}$ harmonic) and $109.1 \mathrm{kHz}$ ( $3^{\text {rd }}$ harmonic), Fig. 6a. Application of the simple estimate [1] indicates a velocity of $4899 \mathrm{~m} \cdot \mathrm{s}^{-1}$ at the fundamental resonance, Fig. 6a. The grout comprises a fine cement in which is distributed rounded gravel aggregate of $\mathrm{mm}$ to $\mathrm{cm}$ diameter. The model used a linear frequency function to accommodate the velocity dispersion and attenuation, shown in Fig. 6b, and overestimates the fundamental $(36.3 \mathrm{kHz})$, but has a good fit to the higher harmonics $(72.6$ and $109.1 \mathrm{kHz})$.

\section{Fig. 6. Reflection spectra of single grout layer used to construct composite targets.}

a. $\quad$ Echo spectra: Solid plot $=$ Experimental; Red dashed plot $=$ Model using properties in Table 1 convolved with transducer sensitivity function. Y-axis: Spectral amplitude (Volts); X-axis: kHz;

b. Equivalent experimental reflectance spectra: Solid plot $=$ Experimental; Red dashed plot $=$ Modelled using properties in Table 1. Y-axis: Relative spectral amplitude normalised by transducer sensitivity function; $X$-axis: $\mathrm{kHz}$;

Only 1D wave propagation effects are captured in the model which assumes a laterally infinite layer comprising a homogeneous medium. The sample face dimensions were limited in size (to $300 \mathrm{~mm}$ square) due to weight handling restrictions; and also, the grout comprised a heterogeneous aggregate including small air bubbles and coarse rounded gravel (to $15 \mathrm{~mm}$ dia) distributed within a fine cement matrix. Hence more complex propagation processes, such as diffraction about the sample edges and scattering off the gravel fill would not be captured in the 1D model, but may have caused some of the differences between the measured and modelled spectra. For example, small fluctuations on the experimental spectra in Figs. 5 and 6, such as at 69 and $73 \mathrm{kHz}$ on the steel spectra and at 49.6 and $66.0 \mathrm{kHz}$ on the grout spectrum, are not captured on the modelled data and may be due to non-1D wave propagation. Note also, non-frequency matching of the peaks on the spectra can be caused by differences in either the velocities or the thicknesses 
in the model compared to the actual sample parameters. For example, a $0.5 \mathrm{kHz}$ difference in the fundamental notch frequency relates to an approximate velocity difference of $70 \mathrm{~ms}^{-1}$ or a thickness difference of $1 \mathrm{~mm}$.

\subsection{Three-Layer Targets}

\subsubsection{Good Condition}

Establishing a steel-grout-steel system in 'good condition' was achieved with firm clamping between the free steel plate and the non-bonded grout face. Test echo data were gathered with the bonded steel plate closest to the transducer (Fig. 2a). The blue plot in Fig. 7 is the magnitude spectrum of the echo gathered from a sample system that was firmly clamped; the green plot is the spectrum of the system under more relaxed clamping. Minor differences between these plots indicate some sensitivity of the system to clamping relaxation. The causes are likely to include reduced contact area between the concrete and the free steel plate as the clamping is relaxed, leading to a reduction in the acoustic loading across the rear interface. Notches on the measured spectra occurred at $54.0,60.5$ and $70.5 \mathrm{kHz}$, with equivalent notches at 53.3, 60.7 and $73.8 \mathrm{kHz}$ on the modelled spectrum. Shallower notches in the measured data indicate a lower quality factor or greater loss compared to the model, and relate especially to damping of the resonance in the front steel. Reduced resonance would be consistent with an improved acoustic match across the araldite bond between the steel and grout but this effect was not tested. Note also that the model treats the grout as a homogeneous material of constant loss, whereas in reality it is a heterogeneous matrix of coarse gravelfilled cement, which may lead to further variability in the grout properties that cannot be accommodated in the model.

Fig. 7. Magnitude spectra of echoes from 3-layer steel-grout-steel classed as 'Good Condition'. Y-axis: relative spectral amplitude (Volts); X-axis: kHz; Solid Plots = Experimental Data; Blue plot 'SGS:-Grout 70 mm:Clamped' = Good Condition; Modelled data (red dashed line) used properties in Table 1.

\subsubsection{Rear Gaps}

Establishing rear gaps of variable apertures was achieved by inserting small metal foil and metallic shims of different thicknesses between the free steel plate and the grout. A series of tests was undertaken whereby the front bonded steel plate was insonified while shims of equal thickness were placed at each of the four corners between the grout and the rear plate. Shim thicknesses of 0.1, 0.3, 0.5, 1.0, 1.5, 2.0, 3.0 and $5.0 \mathrm{~mm}$ were tested.

Fig. 8 shows the magnitude spectra for echoes gathered from targets with rear interface gaps ranging in width from 0.1 to $5 \mathrm{~mm}$ shown by the coloured spectra. With the introduction and growth of a gap from 0.1 $\mathrm{mm}$ to $5 \mathrm{~mm}$, the minimum on the 'good condition' spectrum at $54 \mathrm{kHz}$ (Fig. 8a) shifts to lower frequencies; e.g. $51 \mathrm{kHz}$ at $1 \mathrm{~mm}$ and $49.5 \mathrm{kHz}$ at $5 \mathrm{~mm}$. The spectral notch produced by the minimum also deepens with increasing gap width over this aperture range. The minimum at $60.5 \mathrm{kHz}$ ('good condition') shifts to slightly lower frequencies and diminishes with increasing aperture; e.g. $57.5 \mathrm{kHz}$ at $1 \mathrm{~mm}, 57 \mathrm{kHz}$ at $1.5 \mathrm{~mm}$ and $2 \mathrm{~mm}$ but disappears at $5 \mathrm{~mm}$. There appear to be two other sequences of notch development. The first ia a minimum at $66 \mathrm{kHz}$ apparent on the $0.3 \mathrm{~mm}$ aperture spectrum that shifts to lower frequencies and deepens with increasing aperture; $65.0 \mathrm{kHz}$ at $1 \mathrm{~mm}$ and $63.5 \mathrm{kHz}$ at $5 \mathrm{~mm}$. The notch depth of a second minimum apparent at $72.0 \mathrm{kHz}$ on the $0.1 \mathrm{~mm}$ aperture spectrum initially deepens to $70.0 \mathrm{kHz}$ on the $0.3 \mathrm{~mm}$ spectrum then diminishes with increasing gap aperture.

The minima forming the spectral notches follow a pattern of deepening then shallowing as they shift down frequency. While the minima on the modelled spectra are at different frequencies, similar notch pattern sequences can be mapped from the experimental to the modelled spectra shown in Fig. 8b. For example, the deepening sequence (labelled 1 in Fig. 8) on the experimental spectra from $54.0 \mathrm{kHz}$ (Good Condition) to $49.5 \mathrm{kHz}(5 \mathrm{~mm})$ has an equivalent sequence on the modelled spectra from $53.3 \mathrm{kHz}(\mathrm{GC})$ to $47.4 \mathrm{kHz}(5$ $\mathrm{mm}$ ). The diminishing sequence (2 in Fig. 8) from $60.5 \mathrm{kHz}(\mathrm{GC})$ to $57.0 \mathrm{kHz}(1.5 \mathrm{~mm})$ on the experimental spectra is equivalent to the modelled sequence from $60.8 \mathrm{kHz}(\mathrm{GC})$ to $60.3 \mathrm{kHz}(1.5 \mathrm{~mm})$. The deepening sequence (3) from $66.0 \mathrm{kHz}(0.3 \mathrm{~mm})$ to $63.5 \mathrm{kHz}(5 \mathrm{~mm})$ appears to be similar to the 
modelled sequence from $69.4 \mathrm{kHz}(\mathrm{GC})$ to $62.2 \mathrm{kHz}(5 \mathrm{~mm})$, and which appears to develop from the high frequency notch at $73.8 \mathrm{kHz}$ (modelled GC).

Fig. 8. Magnitude spectra of echoes from 3-layer steel-grout-steel with gaps introduced into the rear interface. Y-axis: relative spectral amplitude (Volts); X-axis: kHz; Black plots:- 'Good condition'; Coloured plots rear gaps; $k^{-}$1. - Notch change patterns used to assess covariance: 1 . Lower frequency; 2 . Central; 3. Upper frequency

\subsubsection{Front Gaps}

A series of tests was undertaken whereby the free steel plate was insonified while shims of equal thickness were placed at each of its four corners, between the grout and this front plate. Again, shim thicknesses of $0.1,0.3,0.5,1.0,1.5,2.0,3.0$ and $5.0 \mathrm{~mm}$ were tested. Fig. 9 shows the magnitude spectra for echoes gathered from targets with front interface gaps ranging in width from 0.1 to $5 \mathrm{~mm}$ shown by the coloured spectra. With increasing gap aperture, the minimum at $54.0 \mathrm{kHz}$ on the good condition spectrum, Fig. 9a, shifts to lower frequencies and initially deepens to $53.0 \mathrm{kHz}$ on the $0.1 \mathrm{~mm}$ spectrum then diminishes with increasing gap aperture, to $52.0 \mathrm{kHz}$ on the $0.3 \mathrm{~mm}$ spectrum, $50.0 \mathrm{kHz}$ on the $3 \mathrm{~mm}$ spectrum and disappears on the $5 \mathrm{~mm}$ spectrum. The minimum at $60.5 \mathrm{kHz}$ also shifts to slightly lower frequencies but grows to a deep notch at $56.5 \mathrm{kHz}$ at $5 \mathrm{~mm}$. Initially, on the introduction of a $0.1 \mathrm{~mm}$ gap, the notch at 70.5 $\mathrm{kHz}$ appears to diminish and a notch develops at $72.5 \mathrm{kHz}$, which then shifts to lower frequencies with larger gap widths to $69.0 \mathrm{kHz}$ at $5 \mathrm{~mm}$. Again, the measured and modelled data exhibit similar notch development patterns. Most obvious is the deepening notch development ( 2 on Fig. 9b) from $60.7 \mathrm{kHz}(\mathrm{GC})$ to $59.3 \mathrm{kHz}$ on the $5 \mathrm{~mm}$ modelled spectrum, while the notch at $53.3 \mathrm{kHz}(\mathrm{GC})$ diminishes with increasing gap aperture to around $48.8 \mathrm{kHz}$ on the $1 \mathrm{~mm}$ spectrum before disappearing ( $1 \mathrm{on} \mathrm{Fig.} \mathrm{9b).} \mathrm{The} \mathrm{small} \mathrm{notch}$ at $73.8 \mathrm{kHz}$ (GC) shifts down in frequency to $67.3 \mathrm{kHz}$ on the $0.5 \mathrm{~mm}$ spectrum before diminishing with increasing gap width (3).

Fig. 9. Magnitude spectra of echoes from 3-layer steel-grout-steel with gaps introduced into the front interface. Y-axis: relative spectral amplitude (Volts); X-axis: kHz; Black plots:- 'Good condition'; Coloured plots front gaps;

\section{$k^{-} \quad$ 1. - Notch change patterns used to assess covariance: 1 . Lower frequency ; 2 . Central; 3 . Upper}

\subsubsection{Water Gaps}

Fig 10a shows the reflection spectra for the echoes gathered from the two steel plates separated by water gaps of 40, 50, 60, 70, 80 and $90 \mathrm{~mm}$. Fig. 10b shows the equivalent modelled spectra for water with an ultrasound velocity of $1450 \mathrm{~m} . \mathrm{s}^{-1}$ with zero attenuation. Resonance in the front steel causes the notches between 56 and $57 \mathrm{kHz}$ on most of the experimental spectra. Some experimental spectra, e.g. 40, 80 and 90 $\mathrm{mm}$ gaps appear to have wider, more complex notches, which relate to coupling between resonance within the steel and a harmonic within the water gap. The clue to this effect is seen in the modelled spectra, which exhibit very narrow width notches that are regularly spaced at a frequency related to the half-wavelength resonance of ultrasound within the water gap, e.g. spaced approximately at $18.1 \mathrm{kHz}$ for a $40 \mathrm{~mm}$ gap and $8.1 \mathrm{kHz}$ for a $90 \mathrm{~mm}$ gap. These features can be sampled on the model spectra, which have a $25 \mathrm{~Hz}$ frequency bin, but are too narrow to be properly sampled by a coarse frequency bin of $0.5 \mathrm{kHz}$ on the experimental spectra ( $2 \mathrm{~ms}$ time window). Widened notches can also be observed on some of the modelled spectra, e.g. for the $50 \mathrm{~mm}$ gap where the $4^{\text {th }}$ harmonic at $58 \mathrm{kHz}\left(60 \mathrm{~mm}\right.$ gaps $/ 5^{\text {th }}$ harmonic at $\left.60.4 \mathrm{kHz}\right)$ is close to the modelled steel resonance of $59 \mathrm{kHz}$.

Fig. 10. Magnitude spectra of echoes from 3-layer steel-water-steel with water gaps of $40 \mathrm{~mm}$ to $90 \mathrm{~mm}$. Y-axis: relative spectral amplitude (Volts); X-axis: kHz; Black plots:- 'Good condition'; Coloured plots water gaps; 1. - Notch change patterns used to assess covariance: 1 . Major central; 2. Minor notch 


\section{Discussion: Distinguishing Grout Condition}

\subsection{Experimental and Modelled Spectra Similarity Tests}

Any broad similarity between the characteristic notches and their patterns of change with condition on both the modelled and experimental spectra can be assessed using simple tests of covariance or dis-similarity. A simple assessment of their covariance can provide an indication of the linear correlation between the experimental and modelled spectra. Table 2 shows the Pearson correlation coefficients from either the frequency location or minimum magnitude of the equivalent notches on the experimental and modelled reflectance spectra. A test of the whole spectrum or sub-section such as from 40 to $80 \mathrm{kHz}$ is not appropriate because the transducer sensitivity function will dominate the covariance and yield a positive correlation. Instead, the test was of equivalent frequencies and magnitudes for key notch features on the spectra from each defect condition: rear gap, front gap or water gap, shown as the numbered sequences in Figs. 8, 9 and 10. While the notches occur at different locations and magnitudes on the experimental and modelled spectra, the high positive covariance between them indicates a strong linear relationship between their causality. The strongest correlation was in the rear-gap condition (Freq - 0.91 / Mag - 0.88), and the weakest on the water gap (no grout) condition, (Freq $-0.88 /$ Mag -0.83 ).

\begin{tabular}{|c|c|c|c|}
\hline \multirow{3}{*}{ Rear Gap } & $\begin{array}{c}\text { Notch } \\
\text { Parameter }\end{array}$ & $\begin{array}{c}\text { Pearson's } \\
\text { Coeff. }\end{array}$ & $\begin{array}{c}\text { K-S } \\
\text { Dissim. }\end{array}$ \\
\hline & Frequency & 0.91 & $0.136(20 \%)$ \\
\hline & Magnitude & 0.88 & $0.227(20 \%)$ \\
\hline \multirow{2}{*}{ Front Gap } & Frequency & 0.842 & $0.368(2 \%)$ \\
\hline & Magnitude & 0.91 & $0.158(20 \%)$ \\
\hline \multirow[t]{2}{*}{ Water Gap } & Frequency & 0.877 & $0.308(10 \%)$ \\
\hline & Magnitude & 0.834 & $0.308(10 \%)$ \\
\hline
\end{tabular}

Table 2. Experimental-modelled spectra similarity expressed as Pearson correlation and Kolmogorov-Smirnov coefficients.

The equality of the frequency location or magnitude of the key notch features can also be assessed using a Kolmogorov-Smirnov dis-similarity test on their normalised cumulative distributions, shown in Fig. 11. This is a simple test that both experimental and modelled distributions are sampled from the same population, where the maximum deviation between the distributions provides the threshold to determine statistical inequality. The frequency location and magnitude are well matched over both the lower and higher frequency notches on the rear gap spectra (Fig. 11a), which exhibit the lowest dis-similarity coefficients (Freq $-0.14 / \mathrm{Mg}-0.23$ ) significant to $20 \%$ (i.e. $<0.266$, which is the $20 \%$ threshold in $\mathrm{K}-\mathrm{S}$ table for the distributions). Lower similarity (i.e. greater dis-similarity) in the front gap condition is related to i. the location and ii. the notch development with gap aperture, including for example, more rapid development of notch sequence 3 on the modelled spectra with narrower gap apertures. In particular, differences in the gap apertures at which notch sequences 1 and 3 deepen and diminish lead to the larger deviations in the distributions between samples 4 to 7 , which capture the divergence in notch sequence 1 between the experimental and modelled spectra and samples 10 to 13 (the divergence in notch sequence 3 see Fig. 11b). Resonance in the front steel is common to all spectra of the water gap condition, but the poor equality between the secondary notch sequence related to water gap resonance ( 2 in Fig. 10) contributes to the lowest covariance and similarity between the experimental and modelled spectra. As discussed above, this may in part relate to the low-frequency resolution in the experimental data not fully sampling these features. The transducer's transient response, with its low sensitivity outside the $30-100 \mathrm{kHz}$ bandwidth, may also mask these features.

Fig. 11. Relative distributions of notch frequency locations and magnitudes of experimental and modelled spectra. a. Rear gap distributions; b. Front gap distributions. 


\subsection{Distinguishing Foundation Grout Condition}

Significant causality for the spectral notches can be attributed to 1D wave propagation through the steelconcrete-steel foundation system. However, minor changes in the modelled parameters can significantly change both the location and magnitude of the spectral notch sequences. For these reasons, and because the in situ (as built) structure may not be known, bespoke empirical approaches are required for distinguishing between different foundation concrete grout conditions. Condition diagnosis based upon ultrasound reflections will require a phase of learning, for example to establish the principal notch patterns associated with the baseline 'good condition' and each of the defective conditions. One possible priority for foundation condition diagnosis may require an order of testing for: i. missing grout (water gap), ii. front gaps and iii. rear gap, i.e. a test order in relation to the strength of the notch features. Significant detection of a water gap (missing grout) would be a critical outcome negating the need to determine the presence of gaps. To ensure confidence in the condition diagnosis, this test will have to rigorously distinguish the echo characteristics of a water gap from a front gap condition, before continuing to test for a rear gap. Both front and rear gaps may be present, but depending upon their strength of influence, their detection may be mutually exclusive. However, it may be possible to sequence the tests and combine the outcomes to rank multiple defect classes, where for example the outcome from the front gap test may also be considered in the rear gap test.

The specific structure of the test sequencing may also be influenced by the signal processing applied to the echo reflections from the foundation. Further consideration should also be given to other forms of echo signal analysis, including the potential condition diagnosis improvements arising from firstly, combined use of the reflection magnitude and phase spectra and secondly, an investigation of the time-frequency variation throughout the signal using tools such as short time Fourier or Wavelet transforms. Improvements arising from the introduction of phase information will depend for example, upon the nature of the phase characteristic, particularly about the resonance notches and their sensitivity to the defect parameters such as crack location and aperture. This could be investigated via an extension of the numerical modelling capability developed by Wilkinson et al. (2018). Time-frequency analysis may offer a means of discriminating characteristic differences in the ring-down in the front steel plate between a water gap and front gap defect. For example, Fig. 12a shows the echo gathered from a steel-water-steel system with a 68 $\mathrm{mm}$ water gap insonified by a linear frequency-modulated chirp of $10 \mathrm{kHz}$ to $110 \mathrm{kHz}$ at an offset of $1.25 \mathrm{~m}$ (during a field trial). The reflected amplitude is low at $58 \mathrm{kHz}$ because of the high transmittance of the steel plates, which is recorded in the amplitude spectrum as a notch (spectrum in Fig. 12a). The other amplitude notch is at $54.9 \mathrm{kHz}$, which is equivalent to the 5 th harmonic of resonance in the water gap $(10.9 \mathrm{kHz})$. The low-amplitude tail, observed from approx. $1.2 \mathrm{~ms}$ on the time series signal (Fig. 12a), has a beat frequency of approximately $3.1 \mathrm{kHz}$, which is the difference between the reverberant frequencies through the steel and the water harmonic. The low-amplitude leakage from $1.2 \mathrm{~ms}$ results from the backward travelling, decaying ring-down of the incident signal from the target system. Leakage (beyond reception of the original excitation signal) is largely absent in a good condition (top-left spectrum in Fig. 12b), and increases in intensity and duration from a rear gap (Fig. 12b top-right), through a front gap (bottom-left) to a water gap condition (bottom-right). Field conditions within operating wind turbines can accommodate temporal sampling windows of circa $2 \mathrm{~ms}$, and hence could support condition class discrimination including tests of the leakage characteristics.

Figure 12. Echo of a $1 \mathrm{~ms}, 10 \mathrm{kHz}-110 \mathrm{kHz}$ linear frequency modulated chirp from a full thickness steel-water-steel system with a $68 \mathrm{~mm}$ water gap.

a. Echo presented as a time series, amplitude spectrum and amplitude contour against time and frequency : Time series plot: Y-axis: +/- 8 Volts; X-axis 0 - 2 ms; Spectrum: Y-axis: 0 - 0.4 V; X-axis: 10 - 120 kHz; Spectrogram: Y-axis: 0 - $120 \mathrm{kHz}$; X-axis: 0 - $2 \mathrm{~ms}$

b. Spectrograms for: Top row-Left: Good Condition;

Bottom row-Left: $1 \mathrm{~mm}$ front gap;

Top row-Right: $1 \mathrm{~mm}$ rear gap;

Bottom row-Right: $68 \mathrm{~mm}$ water gap

\section{Conclusions}

This study has compared the magnitude spectra of modelled and experimental reflected echoes from a layered structure representing a monopile wind turbine foundation. The model outcomes were produced by 
a transfer matrix representation of 1D wave propagation backscattered from an arbitrary layered system reported by Wilkinson et al. (2018) [1]. The experimental apparatus and methodology were developed to enable testing on true thickness-scale samples of limited lateral dimensions to conform with a restricted laboratory environment. This included insonifying targets over a $10 \mathrm{kHz}$ to $120 \mathrm{kHz}$ frequency range using a bespoke piezocomposite transducer to transceive sequences of overlapping cosine FM chirps, each spanning $50 \mathrm{kHz}$ over a $400 \mu$ s pulse width.

Reflectance spectra of echoes from targets comprising a $70 \mathrm{~mm}$ concrete grout between two $50 \mathrm{~mm}$ mild steel plates have been presented. Local minima on the reflectance spectra occurred at frequencies associated with half-wavelength resonance within the steel and concrete layers comprising these structures. While heterogeneity, mis-matched properties, i.e. density, ultrasound velocity and attenuation between the test and the model samples, and non-1D processes such as scattering, lead to different signature characteristics, the experimental and modelled spectra exhibited significant equality. Strong positive correlations between the frequency locations and magnitudes of the notches on the experimental and modelled spectra provide very significant evidence that backscattered wave propagation normal to the transducer face is the principal process modulating the incident signal.

Matching notch sequences related to fundamental resonance in the steel plates and harmonics within the water gaps influenced the level of equality of the normalised notch magnitude and location distributions, which was greatest on the rear gap condition spectra and lowest on water gap spectra. Poor experimental resolution of the water gap harmonics possibly contributed to lower equality between the modelled and experimental spectra for the water gap condition. However, beating between the fundamental resonance in the steel plates and harmonics within the water gaps was better captured in field data gathered using longer duration pulse excitation and sampling windows. Introduction of water-filled gaps between the steel and concrete, and also replacement of the grout with water between the steel plates, produced recognisable patterns of change to the spectral notch frequencies and magnitudes that can potentially be used as a means of diagnosing these defects in the original as-built foundation structure. Deployment of the ultrasound instrumentation and sensor from a remotely operated vehicle (ROV) was trialled by Brett et al. (2018) [3] who gathered very high quality, long duration echoes from operating wind turbines. These signals exhibited the above-described time varying spectral characteristics demonstrating the potential for the use of an ROVdeployed low-frequency ultrasound method for routine inspection of wind turbine condition.

Crucially, the introduction of an automated condition classification capability would remove the overhead of expert interpretation and enable rapid asset surveying by commercial operators. Optimal service would incorporate real-time classification differentiating classes based on: a. grout layer presence (absence), b. gap presence and c. gap location. Algorithms supporting the automated condition classification are yet to be developed, but a successful approach based on the decomposition of time-localised features linked to reverberation within specific layers of the foundation structure is anticipated. Thereafter, type spectrograms for each key state may be devised and combined with the original amplitude spectra for improved classification of the echo signals, including using goodness of fit as a measure of classification certainty.

\section{Acknowledgements}

The numerical wave propagation model was developed as part of the EPSRC-funded Biologically Inspired Acoustic Systems project (EP/C523776/1). The research and findings relating to monopile wind turbine foundations were supported by the NERC-funded Wind Turbine Foundation Ultrasonic Spectral Characterisation project (NE/M008444/1) and the E.On New Build and Technology Ltd. (now Uniper Technologies Ltd.) contract 4500070630/817/2122. The contributions of Wilkinson, Gunn, Dashwood, Holyoake, Wallis, Leman and Rees are published with the permission of the Executive Director of the British Geological Survey.

\section{References}

1. Wilkinson P.B., Gunn D.A., Dashwood, B.A.J., Holyoake S.J., Brett, C.R. \& Rees, J. (2018). Application of low-frequency acoustic and ultrasound to characterise layered media. NDT\&E Int. ISSN: 0963-8695, Vol: 96, Page: $35-46$. 
2. Iliopoulos, AN, Van Hemelrijck. D, Vlassenbroeck, J \& Aggelis, DG. Assessment of grouted samples from monopile wind turbine foundation using combined non-destructive techniques. Const. \& Build. Mat., 2016, V122, 855-862.

3 .Brett, C.R., Gunn, D.A., Dashwood, B.A.J., Holyoake, S.J. \& Wilkinson, P.B., (2018). Development of a technique for inspecting the foundations of offshore wind turbines Insight - the Journal of the British Institute of NDT, Jan 2018, Volume 60, Number 1, January 2018, pp. 19-27..

4. Carbon Trust: Offshore Wind Accelerator Competition: Sub-sea Inspections Methods. www.carbontrust.com/about-us/tenders/offshore-wind-accelerator-competition-sub-sea-inspection-methods/

5. Gooberman, G.L., (1968). Ultrasonics Theory and Application. The English Universities Press, London, 210p. ISBN: 03400514699780340051467.

6. Krautkramer, J. \& Krautkramer, H., (1990). Ultrasonic Testing of Materials. $4^{\text {th }}$ Ed. Springer Verlag, November 1990, 677p. ISBN: 0387512314.

7. Hopper, C., Assous, S., Gunn, D.A., Jackson, P.D., Wilkinson, P.B., Rees, J.R., O'Leary, R.L.\& Lovell, M.A., (2012). Bio-inspired low-frequency material characterisation. Advances in Acoustics and Vibration. Research Article 927903, 1-12.

8. ITW Engineered Polymers ApS., (2016). http://densit.com/products/renewable-energy-foundationsolutions/ducorit-offshore/

\section{Figure Captions:}

Fig. 1. Principal foundation for offshore infrastructure constructed on the seabed.

a. Schematic section through a wind turbine monopile foundation structure.

b. Concept of reverberating ultrasound within each layer of the foundation structure.

Fig. 2. Experimental echo reflection tests from the physical foundation condition models.
a. Incident ultrasound relative to the four key foundation model condition states.
b. Steel-Grout bond: steel cleaned and araldite applied over mould surface.
c. Steel-Grout bond: $70 \mathrm{~mm}$ grout block clamped to underlying steel while araldite cures.

Fig. 3. Experimental set-up and instrumentation used to record reflected and transmitted signals.

Fig. 4. Measuring the transducer sensitivity function using echo from the air-water interface.
a. Transducer in tank directed at the water surface for air-water reflection test.
b. Series of received signals for the successive CFM chirps (each with a $50 \mathrm{kHz}$ frequency range).
c. Transducer sensitivity function constructed from the envelope of the spectral response to each of the CFM signals.

Fig. 5. Reflection spectra of single steel layers used to construct composite targets.

a. $\quad$ Echo spectra: Solid plots $=$ Experimental; Red dashed plot $=$ Model using properties in Table 1 convolved with transducer sensitivity function; $\mathrm{Y}$-axis: Spectral amplitude (Volts); X-axis: $\mathrm{kHz}$.

b. $\quad$ Equivalent experimental reflectance spectra: Solid plots = Experimental; Red dashed plot = Modelled using properties in Table 1. Y-axis: Relative spectral amplitude normalised by transducer sensitivity function; $\mathrm{X}$-axis: $\mathrm{kHz}$.

Fig. 6. Reflection spectra of single grout layer used to construct composite targets.

a. $\quad$ Echo spectra: Solid plot $=$ Experimental; Red dashed plot $=$ Model using properties in Table 1 convolved with transducer sensitivity function. Y-axis: Spectral amplitude (Volts); X-axis: $\mathrm{kHz}$.

b. Equivalent experimental reflectance spectra: Solid plot $=$ Experimental; Red dashed plot $=$ Modelled using properties in Table 1. Y-axis: Relative spectral amplitude normalised by transducer sensitivity function; X-axis: $\mathrm{kHz}$. 
Fig. 7. Magnitude spectra of echoes from 3-layer steel-grout-steel classed as 'Good Condition'. Y-axis: relative spectral amplitude (Volts); X-axis: kHz; Solid Plots = Experimental Data; Blue plot 'SGS:-Grout 70 mm:Clamped' = Good Condition; Modelled data (red dashed line) used properties in Table 1.

Fig. 8. Magnitude spectra of echoes from 3-layer steel-grout-steel with gaps introduced into the rear interface. Y-axis: relative spectral amplitude (Volts); X-axis: kHz; Black plots:- 'Good condition'; Coloured plots rear gaps; $k^{-}$1. - Notch change patterns used to assess covariance: 1 . Lower frequency; 2 . Central; 3. Upper frequency

Fig. 9. Magnitude spectra of echoes from 3-layer steel-grout-steel with gaps introduced into the front interface. Y-axis: relative spectral amplitude (Volts); X-axis: kHz; Black plots:- 'Good condition'; Coloured plots front gaps;

L- 1. - Notch change patterns used to assess covariance: 1. Lower frequency; 2. Central; 3. Upper

Fig. 10. Magnitude spectra of echoes from 3-layer steel-water-steel with water gaps $\mathbf{4 0} \mathrm{mm}$ to $90 \mathrm{~mm}$. Y-axis: relative spectral amplitude (Volts); X-axis: kHz; Black plots:- 'Good condition'; Coloured plots water gaps;

1. - Notch change patterns used to assess covariance: 1 . Major central; 2. Minor notch

Fig. 11. Relative distributions of notch frequency locations and magnitudes of experimental and modelled spectra. a. Rear gap distributions: Notch Frequency and Notch Magnitude.

b. Front gap distributions: Notch Frequency and Notch Magnitude.

Figure 12. Echo of a $1 \mathrm{~ms}, 10 \mathrm{kHz}-110 \mathrm{kHz}$ linear frequency modulated chirp from a full thickness steel-water-steel system with a $68 \mathrm{~mm}$ water gap.

a. Echo presented as a time series, amplitude spectrum and amplitude contour against time and frequency : Time series plot: Y-axis: +/- 8 Volts; X-axis 0 - 2 ms; Spectrum: Y-axis: 0 - 0.4 V; X-axis: 10 - $120 \mathrm{kHz}$ Spectrogram: Y-axis: 0 - $120 \mathrm{kHz}$; X-axis: 0 - 2 ms

b. Spectrograms for: Top row-Left: Good Condition; Top row-Right: $1 \mathrm{~mm}$ rear gap; Bottom row-Left: $1 \mathrm{~mm}$ front gap; Bottom row-Right: $68 \mathrm{~mm}$ water gap 
Fig. 1. Principal foundation for offshore infrastructure constructed on the seabed.

a. Schematic section through a wind turbine monopile foundation structure.

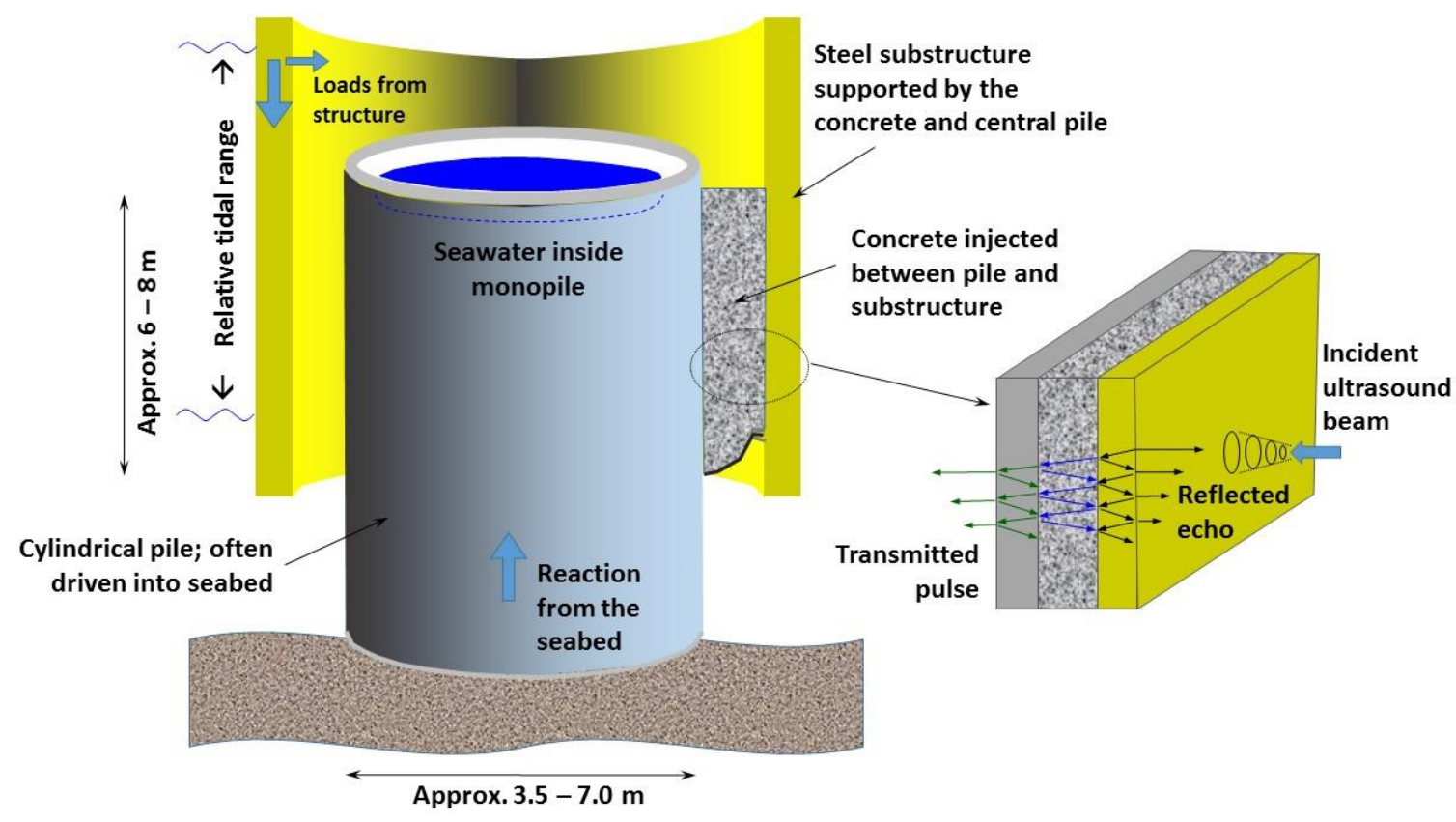

Fig. 1. Principal foundation for offshore infrastructure constructed on the seabed.

b. Reverberation of incident sound wave energy that penetrates a finite thickness layer and is partially reflected at the interfaces between the layer and bounding media; example shows a single layer bounded by water. The spectra of the reflection for a fundamental frequency of $59 \mathrm{kHz}$, such as produced by a $50 \mathrm{~mm}$ mild steel plate.

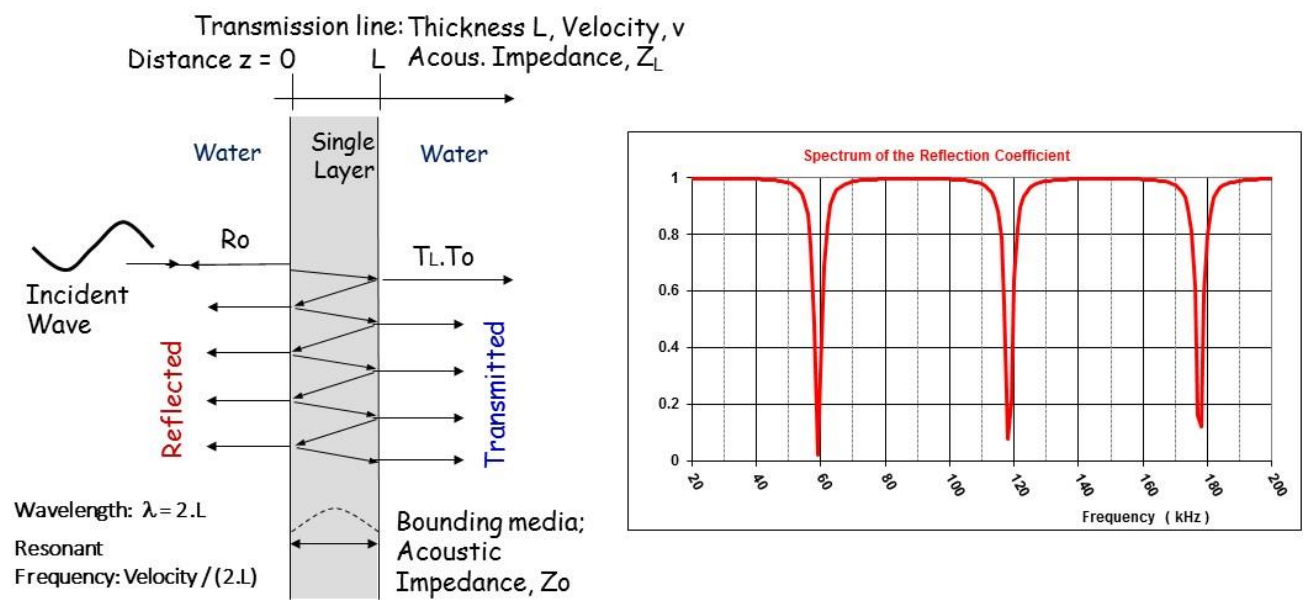




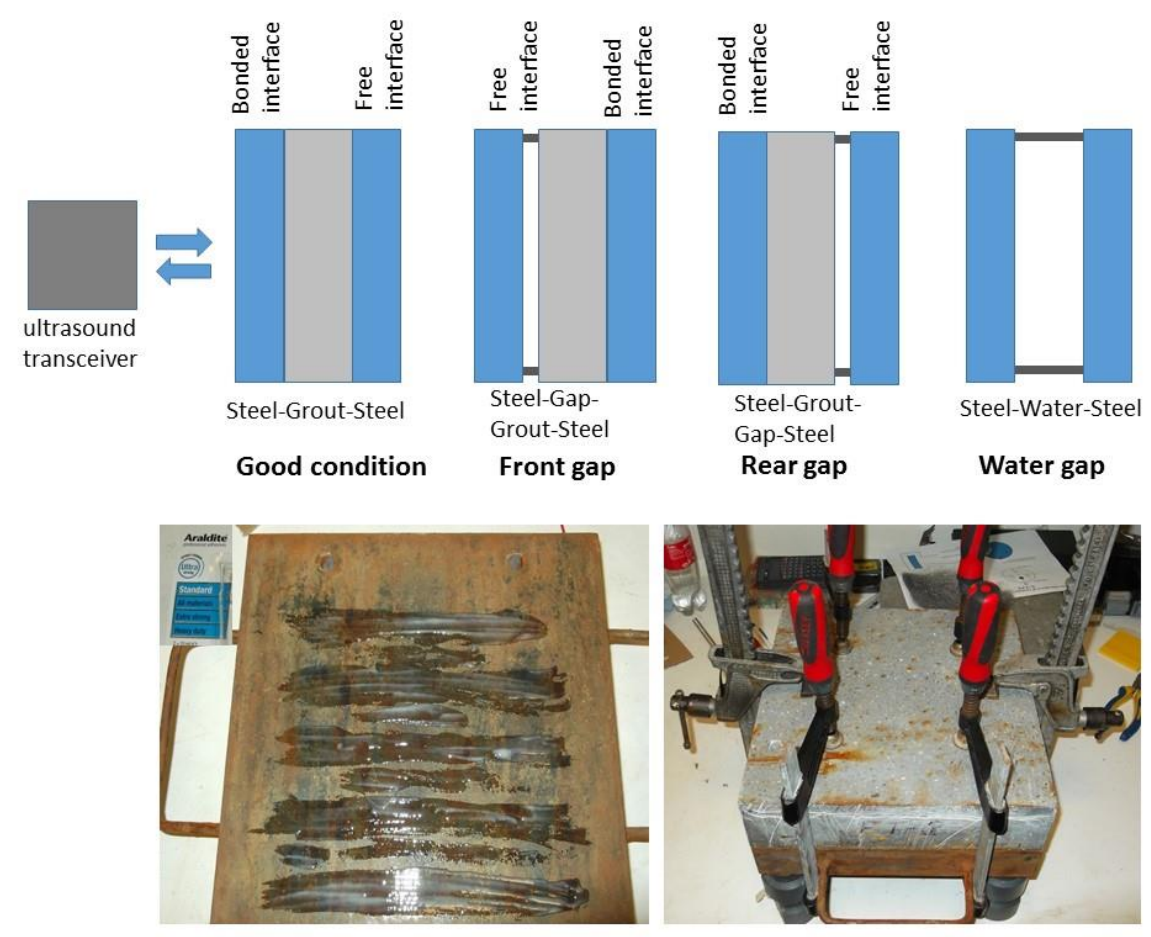

Fig. 2. Set-up for the experimental tests of the echo reflections from the foundation condition physical models.

a. Incident ultrasound relative to the four key foundation model condition states.

b. Steel-Grout bond: steel cleaned and araldite applied over mould surface.

c. Steel-Grout bond: $70 \mathrm{~mm}$ grout block clamped to underlying steel while araldite cures.

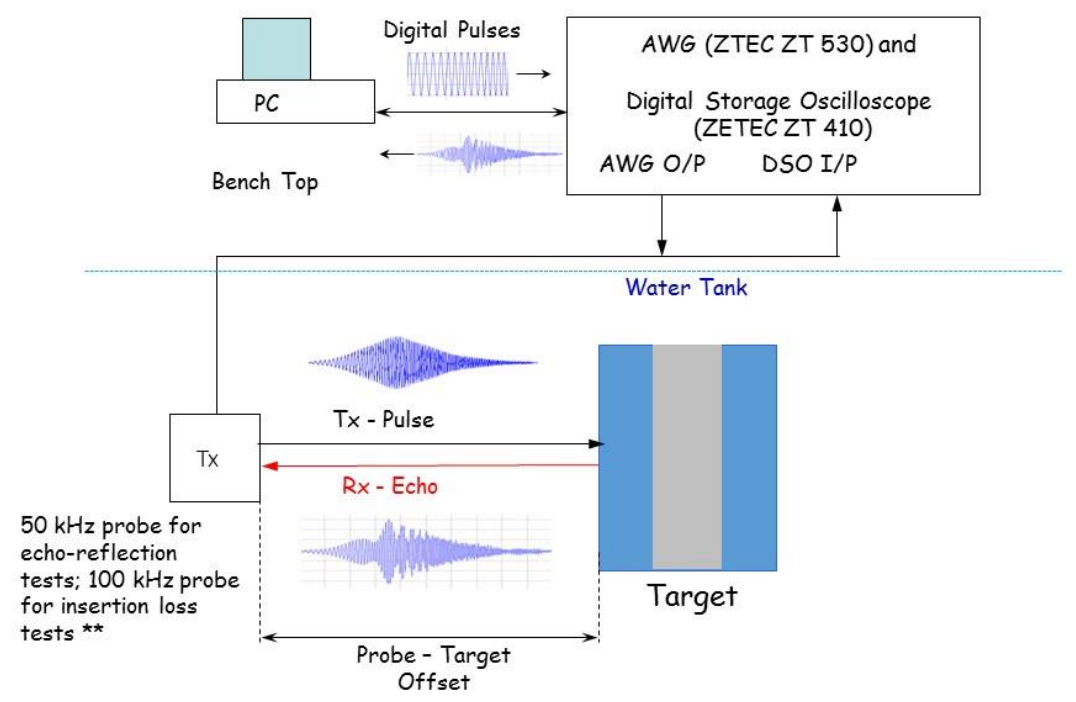

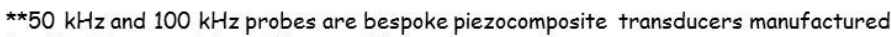
by Alba Ultrasound Ltd., Glasgow, UK.

Figure 3. Experimental set-up and instrumentation used to record reflected and transmitted signals. 
Fig. 4. Measuring the transducer sensitivity function using echo from the air-water interface.

a. Transducer in tank directed at the water surface for air-water reflection test.

b. Series of received signals for the successive CFM chirps (each with a $50 \mathrm{kHz}$ frequency range).

c. Transducer sensitivity function constructed from the envelope of the spectral response to each of the CFM signals.
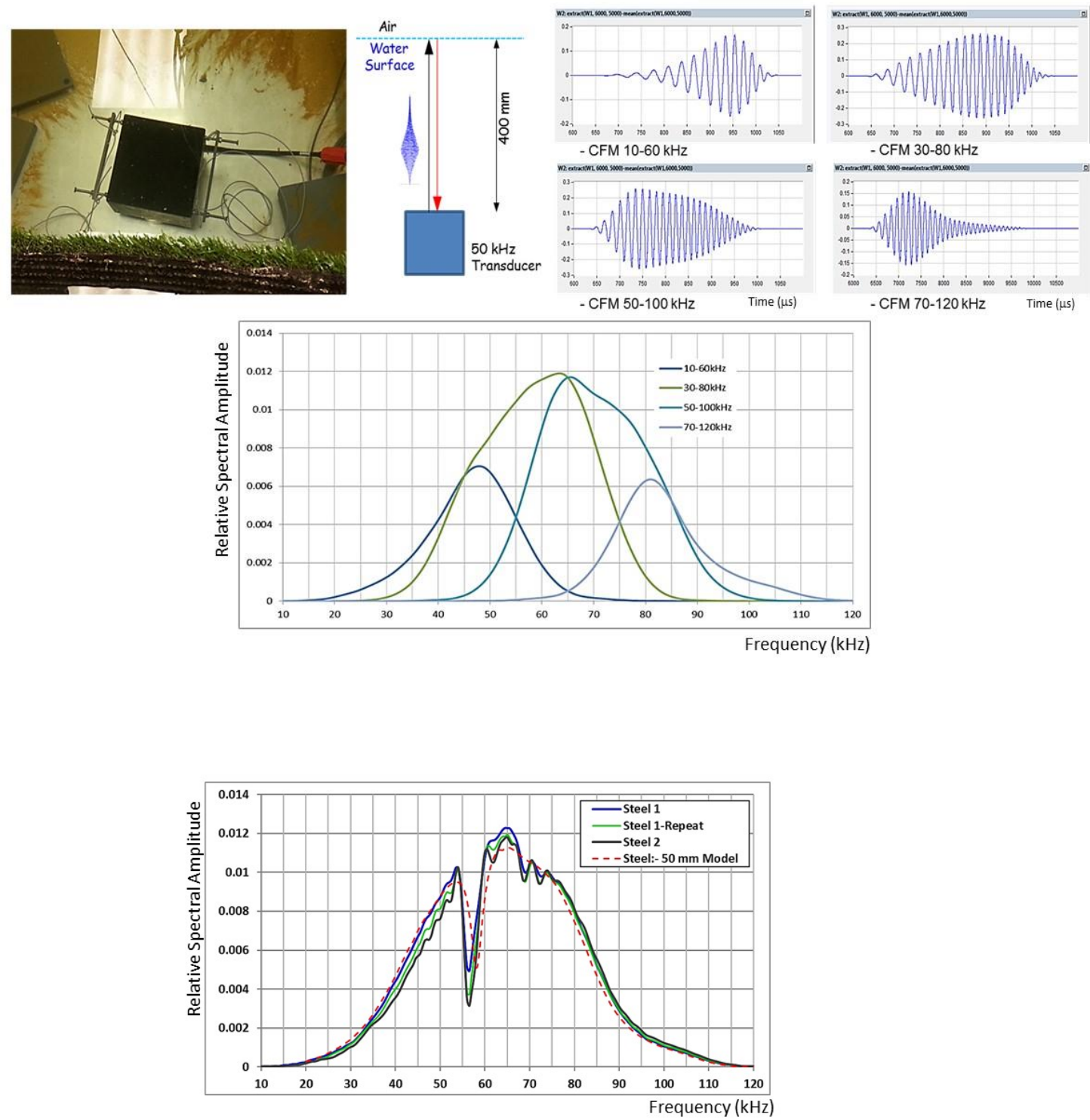

a. Echo spectra: Solid plots $=$ Experimental; Red dashed plot $=$ Model using properties in Table 1 convolved with transducer sensitivity function. Y-axis: Spectral amplitude (Volts); X-axis: kHz;

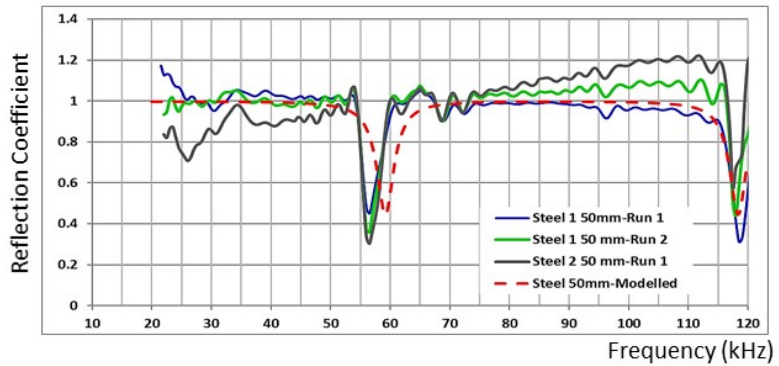

b. Equivalent experimental reflectance spectra: Solid plots = Experimental; Red dashed plot $=$ Modelled using properties in Table 1. Y-axis: Relative spectral amplitude normalised by transducer sensitivity function; $\mathrm{X}$-axis: $\mathrm{kHz}$;

Fig. 5. Reflection spectra of single steel layers used to construct composite targets. 


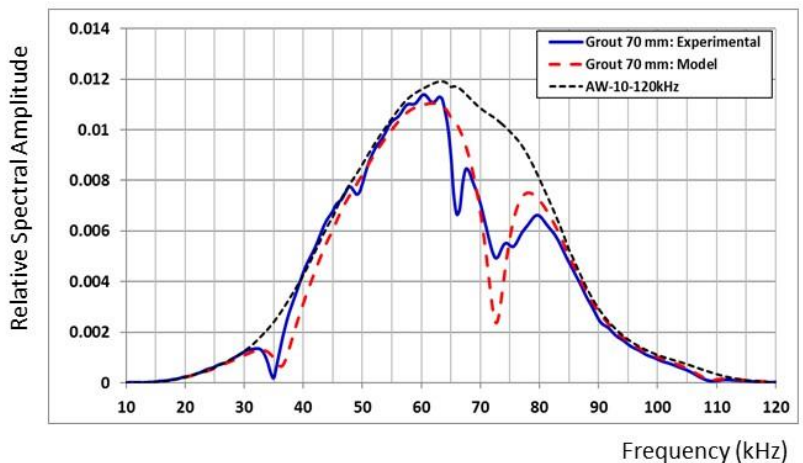

a. Echo spectra: Solid plot $=$ Experimental; Red dashed plot $=$ Model using properties in Table 1 convolved with transducer sensitivity function.

Y-axis: Spectral amplitude (Volts); X-axis: kHz;

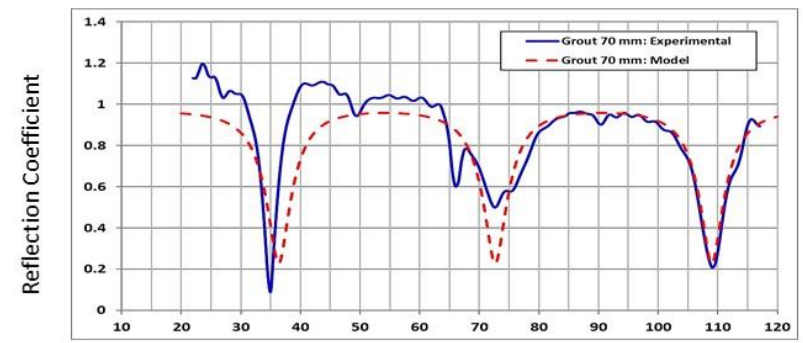

Frequency $(\mathrm{kHz})$

b. Equivalent experimental reflectance spectra: Solid plot = Experimental; Red dashed plot $=$ Modelled using properties in Table 1. Y-axis: Relative spectral amplitude normalised by transducer sensitivity function; $\mathrm{X}$-axis: $\mathrm{kHz}$;

Fig. 6. Reflection spectra of single grout layer used to construct composite targets.

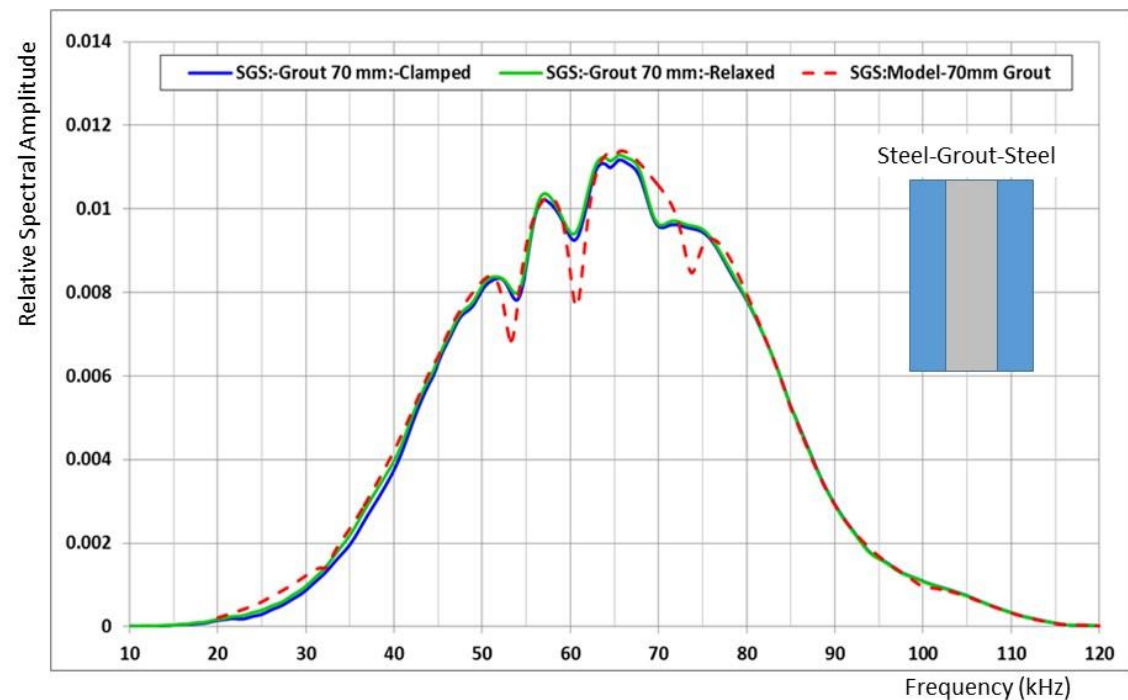

Fig. 7. Magnitude spectra of echoes from 3-layer steel-grout-steel classed as 'Good Condition'.

Y-axis: relative spectral amplitude (Volts); X-axis: kHz; Solid Plots = Experimental Data; Blue plot 'SGS: Grout 70 mm:-Clamped' = Good Condition; Modelled data (red dashed line) used properties in Table 1. 

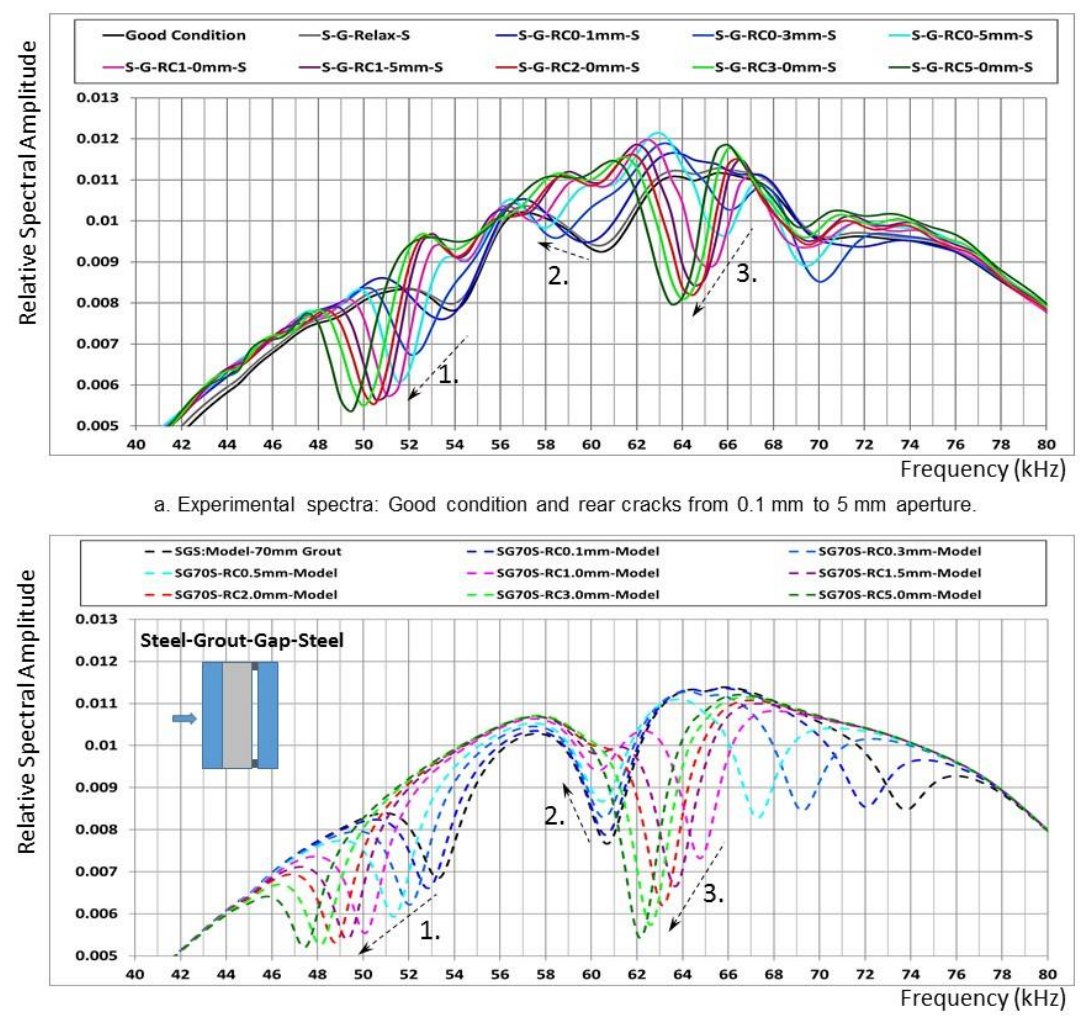

b. Modelled spectra: Good condition and rear cracks from $0.1 \mathrm{~mm}$ to $5 \mathrm{~mm}$ aperture.

Fig. 8. Magnitude spectra of echoes from 3-layer steel-grout-steel with gaps introduced into the rear interface. Y-axis: relative spectral amplitude (Volts); X-axis: kHz; Black plots:- 'Good condition'; Coloured plots rear gaps;

2.- 1. - Notch change patterns used to assess covariance: 1 . Lower frequency; 2. Central; 3. Upper frequency

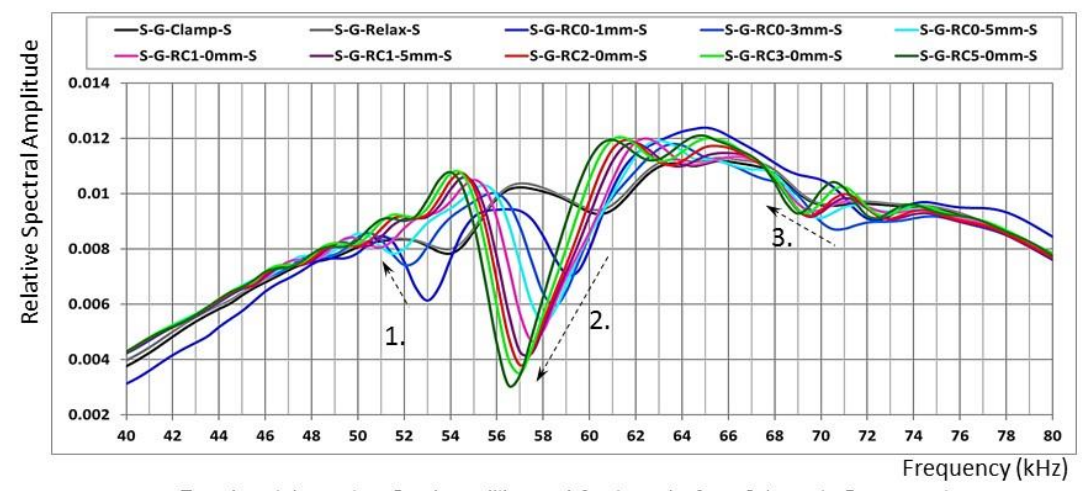

a. Experimental spectra: Good condition and front cracks from $0.1 \mathrm{~mm}$ to $5 \mathrm{~mm}$ aperture.

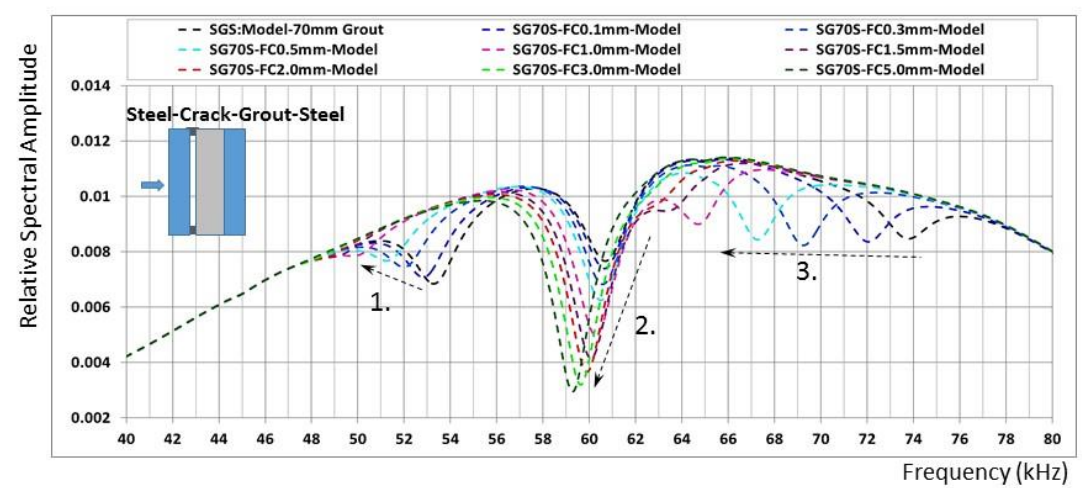

b. Modelled spectra: Good condition and front cracks from $0.1 \mathrm{~mm}$ to $5 \mathrm{~mm}$ aperture.

Fig. 9. Magnitude spectra of echoes from 3-layer steel-grout-steel with gaps introduced into the front interface. Y-axis: relative spectral amplitude (Volts); X-axis: kHz; Black plots:- 'Good condition'; Coloured plots front gaps;

-1. - Notch change patterns used to assess covariance: 1. Lower frequency ; 2. Central; 3. Upper 


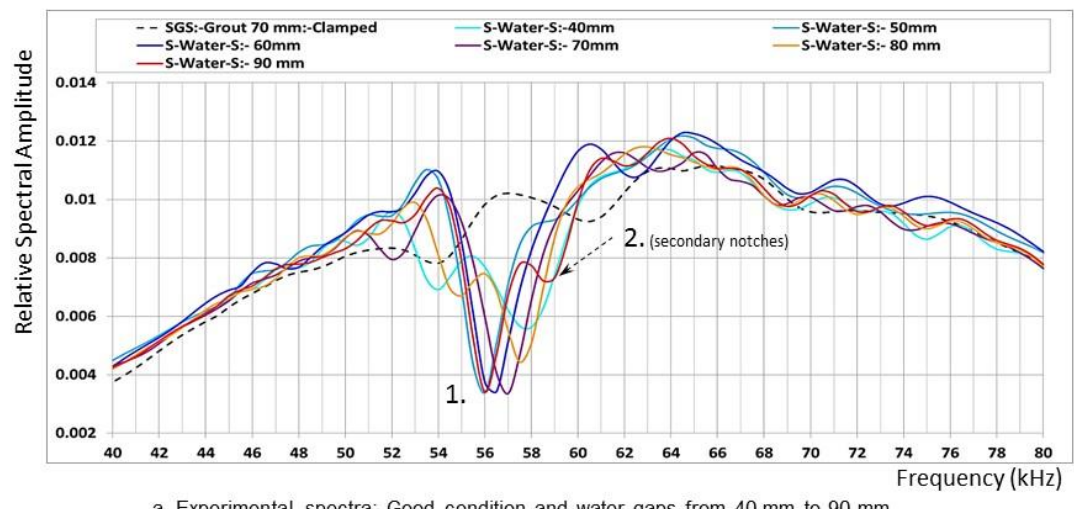

a. Experimental spectra: Good condition and water gaps from $40 \mathrm{~mm}$ to $90 \mathrm{~mm}$

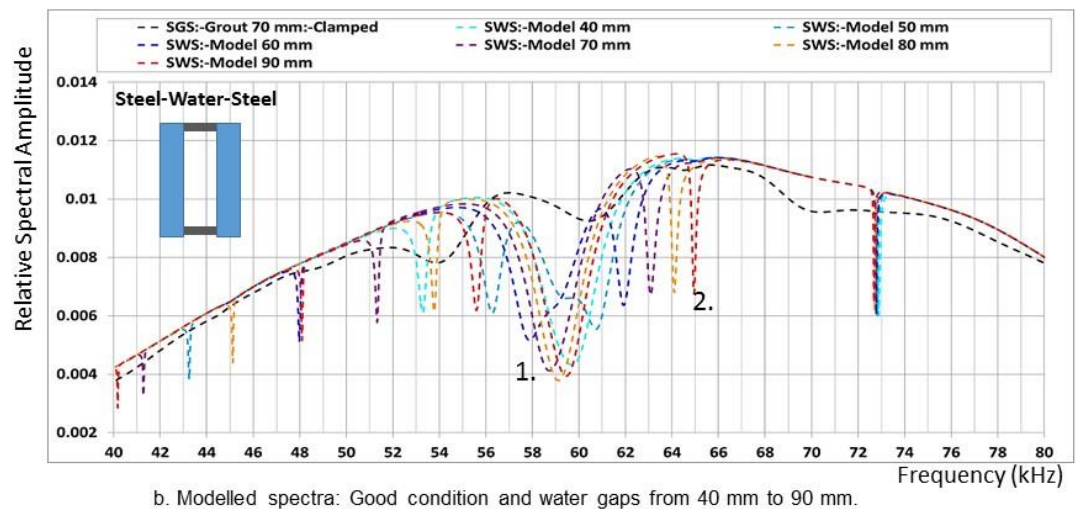

Fig. 10. Magnitude spectra of echoes from 3-layer steel-water-steel with water gaps $40 \mathrm{~mm}$ to $90 \mathrm{~mm}$.

Y-axis: relative spectral amplitude (Volts); X-axis: kHz; Black plots:- 'Good condition'; Coloured plots water gaps;

1. - Notch change patterns used to assess covariance: 1 . Major central; 2. Minor notch
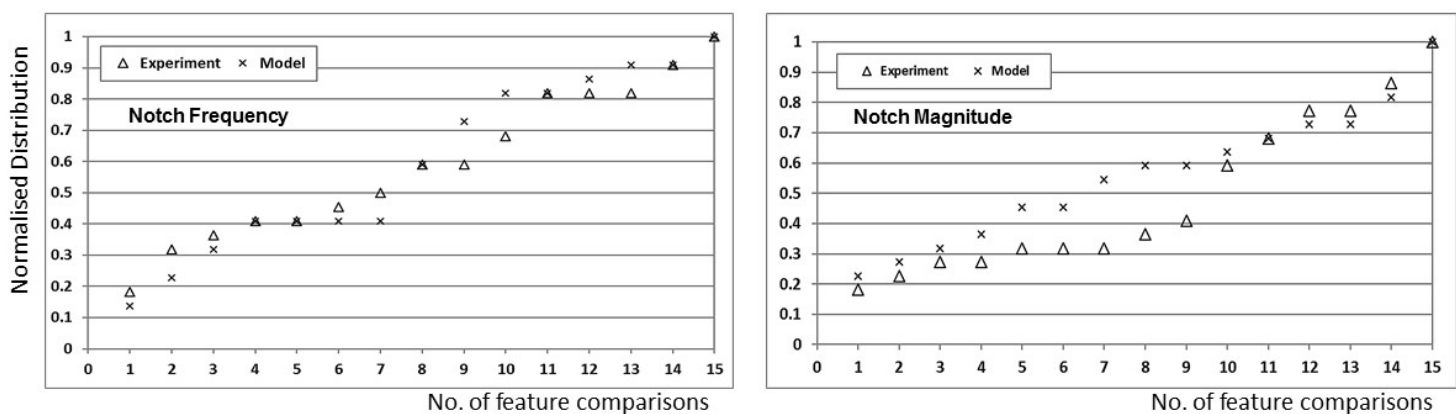

a. Rear gap distributions: Notch Frequency and Notch Magnitude.
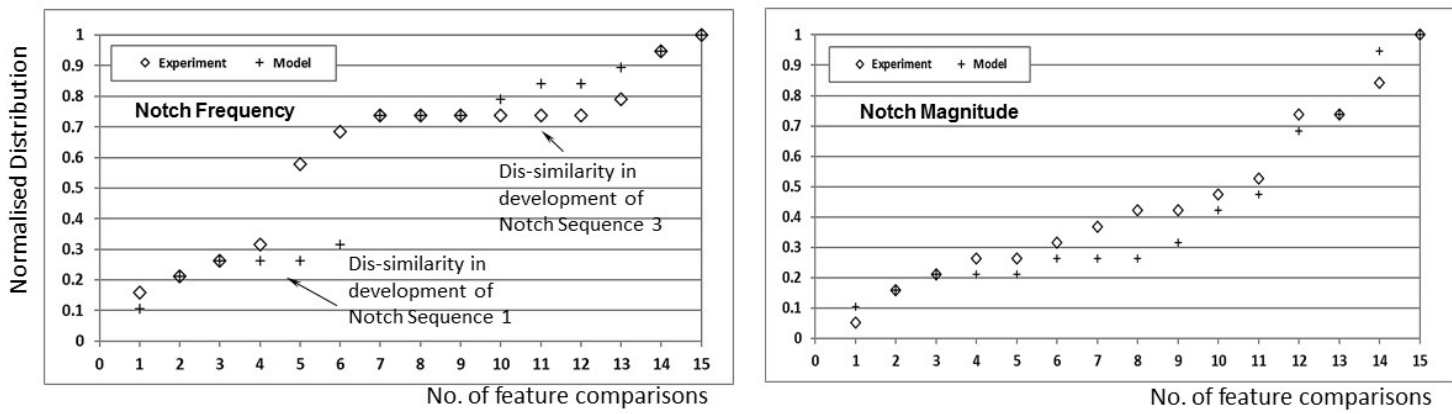

b. Front gap graphs: Notch Frequency and Notch Magnitude

Fig. 11. Relative distributions of notch frequency locations and magnitudes of experimental and modelled spectra. 


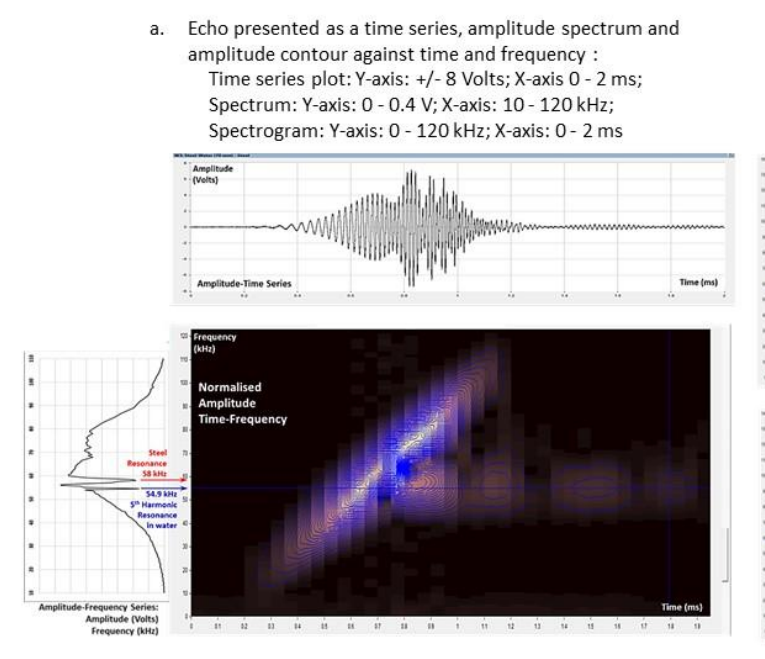

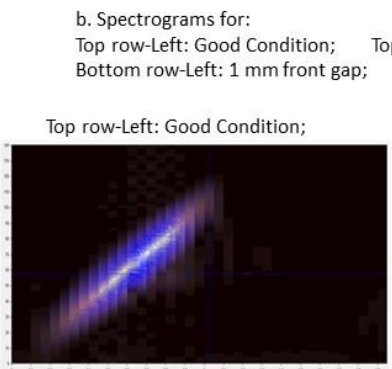

Bottom row-Left: $1 \mathrm{~mm}$ front gap;

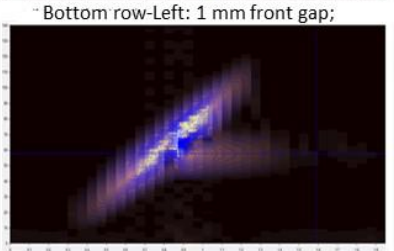

Top row-Right: $1 \mathrm{~mm}$ rear gap; Bottom row-Right: $68 \mathrm{~mm}$ water gap

Top row-Right: $1 \mathrm{~mm}$ rear gap;

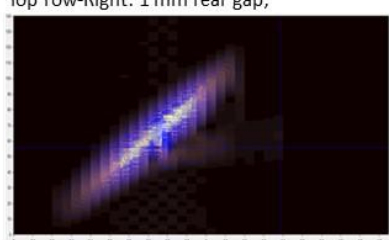

Bottom row-Right: $68 \mathrm{~mm}$ water gap

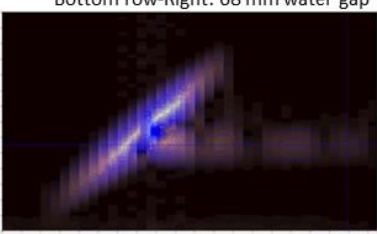

Figure 12. Echo of a $1 \mathrm{~ms}, 10 \mathrm{kHz}-110 \mathrm{kHz}$ linear frequency modulated chirp from a full thickness steel-water-steel system with a $68 \mathrm{~mm}$ water gap.

a. Echo presented as a time series, amplitude spectrum and amplitude contour against time and frequency :

Time series plot: Y-axis: +/- 8 Volts; $X$-axis 0 - 2 ms;

Spectrum: Y-axis: $0-0.4 \mathrm{~V}$; X-axis: $10-120 \mathrm{kHz}$;

Spectrogram: Y-axis: 0 - $120 \mathrm{kHz}$; X-axis: 0 - $2 \mathrm{~ms}$

b. Spectrograms for: Top row-Left: Good Condition;

Top row-Right: $1 \mathrm{~mm}$ rear gap; Bottom row-Left: $1 \mathrm{~mm}$ front gap; 